\title{
Developmental effects of the uterine environment: dependence on fetal sex in rats
}

\author{
W. F. Ward, C. H. Karp and H. Aceto, Jr* \\ Department of Radiology, Northwestern University Medical School, Chicago, Illinois 60611, \\ and ${ }^{*}$ College of William and Mary, Virginia Associated Research Campus, \\ Newport News, Virginia 23606, U.S.A.
}

\begin{abstract}
Summary. Body weight was recorded as a function of intrauterine position for 20-dayold male and female rat fetuses from 83 normal litters.

Male fetuses located in the middle of the uterine horn were invariably heavier than males located at the extreme ovarian or cervical positions, those at intermediate positions being intermediate in size. The mean body weight of male fetuses was inversely related to the number of fetuses present in the ipsilateral uterine horn. The body weight of female fetuses appeared independent of both intrauterine position and ipsilateral uterine occupancy. For both sexes, fetal body weight was inversely related to the number of littermates in the contralateral horn.

Male fetuses were significantly larger than female fetuses under all but the most adverse intrauterine conditions. Therefore, random fluctuations in sex ratio may distort the true relationship between mean fetal weight and intrauterine position, if the two sexes are not analysed separately.
\end{abstract}

\section{Introduction}

In polytocous species with bicornuate uteri, fetal body weight is inversely proportional to the number of fetuses present in both the ipsilateral and the contralateral uterine horns (Ibsen, 1928; Hammond, 1935; Barcroft, 1944; Eckstein \& McKeown, 1955; Hashima, 1956; McLaren \& Michie, 1959, 1960; Healy, McLaren \& Michie, 1960; McCarthy, 1965; McLaren, 1965; Barr, Jensh \& Brent, 1969, 1970). This influence of the uterine environment has been explained on the basis of competition among fetuses for a relatively limited supply of nutrients (Ibsen, 1928; Hammond \& Marshall, 1952; McCance, 1962), space (Ibsen, 1928; Barcroft, 1944; McLaren, 1965), and/or uterine vasculature (Eckstein, McKeown \& Record, 1955; McCance, 1962; McLaren, 1965).

Fetal growth is also affected by intrauterine position, although species differ in the location of the most and least favourable developmental sites (Ibsen, 1928; Rosahn \& Greene, 1936; Mossman, 1937; Hashima, 1956; Waldorf, Foote, Self, Chapman \& Casida, 1957; McLaren \& Michie, 1959, 1960; Healy et al., 1960; McLaren, 1965; Barr et al., 1969, 1970). Intrauterine position effects have been attributed to differential implantation time (Mossman, 1937), uteroplacental haemodynamics (McLaren \& Michie, 1959, 1960; Healy et al., 1960; McLaren, 1965), mechanical constraints imposed by the uterus (Ibsen, 1928; McLaren, 1965), and other unknown factors (Barr \& Brent, 1970).

Previous studies of uterine environmental effects in general, and of positional effects in particular, have assumed that the developmental influences exerted are similar for male and female fetuses. It is also assumed that the placenta mediates some, if not all, of these developmental influences, since fetal and placental weights tend to respond similarly to environmental conditions (Barcroft, 1944; Eckstein et al., 1955; McCance, 1962; McCarthy, 1965, 1967; McLaren, 1965).

To test these assumptions in the rat, we have analysed separately the effect of the uterine environment on the growth of male and female fetuses and their placentae.

\section{Materials and Methods}

A total of 83 nulliparous Sprague-Dawley rats (Blue Spruce Farms, Altamount, New York) weighing $180-220 \mathrm{~g}$ were mated with males of the same strain. Day 1 of pregnancy was defined as the day copulatory plugs were observed. 
All animals were housed at $23 \pm 2{ }^{\circ} \mathrm{C}$ under $12 \mathrm{~h}$ fluorescent light $(06.00-18.00 \mathrm{~h}) /$ day and were given food (Purina Lab Chow, Ralston Purina Co., St. Louis, Mo.) and water ad libitum. On the 20th day of pregnancy, animals were killed by an overdose of ether, and their uteri were examined for live and dead fetuses and resorption sites. Fetal and placental weights were recorded. The fetuses were then dissected, and their sex was determined by gonadal morphology. All data were recorded with respect to intrauterine position. Statistical analyses were performed as described by Dixon \& Massey (1957), and the data were expressed as the mean \pm S.E.M.

\section{Results}

The 83 litters comprised 10.8 $\pm 0 \cdot 1$ implantations (range 5-16) and 10.2 $\pm 0 \cdot 2$ live fetuses (range $3-16$ ). Individual uterine horns contained from 1 to 10 implantations and live fetuses. Of the 166 uterine horns $29(17.5 \%)$ contained one or more resorption sites, i.e. the remains of embryos which had died after implantation. These horns were excluded from the analysis of intrauterine position effect, since resorption sites had a variable effect on the spacing of the surviving fetuses.

The right uterine horns contained $52.4 \%$ of all implantations, $4.7 \%$ of which were resorption sites. Of the implantations in the left uterine horns, $4.2 \%$ were resorption sites. The fetal sex ratios (males/100 females) in the right and left horns, 102 and 100 respectively, were not significantly different. There was no significant difference in average body weight of fetuses in the right $(2 \cdot 13 \pm$ $0 \cdot 01 \mathrm{~g})$ and left $(2 \cdot 10 \pm 0.01 \mathrm{~g})$ uterine horns, and the data from the two sides were therefore pooled for analysis.

Regardless of the number of fetuses present, males located in the middle of the uterine horn were invariably heavier than those occupying either of the extreme positions (Table 1). Those occupying intermediate positions were intermediate in size. The body weight of female fetuses, however, did not show any regular pattern in relation to intrauterine position (Table 1).

The weight of male fetuses appeared to be inversely related to the number of fetuses present in the ipsilateral uterine horn (Table 1). This negative growth influence exerted on male fetuses by increasing uterine occupancy did not fall equally on all members, however: the weight of male fetuses occupying the middle uterine position varied only slightly as numbers increased, but the males occupying the abcentric positions, particularly the extreme positions, decreased in size as the horn became increasingly crowded (Table 1). In contrast, the body weight of female fetuses appeared to be independent of the number of fetuses present in the ipsilateral horn (Table 1).

The body weight of male and female fetuses showed a steady decline as the number of littermates present in the contralateral uterine horn increased (Table 2). This relationship was observed for male fetuses regardless of their intrauterine position. Moreover, average fetal weight in one horn of a litter was positively related to, rather than independent of, average fetal weight in the contralateral horn, regardless of the number or sex of the fetuses involved (Table 2).

On the 20th day of gestation, male fetuses were almost invariably larger than female fetuses (Table 1), the exceptions being some males located at the extreme ovarian or cervical positions of crowded uterine horns (Table 1). The body weight of fetuses was independent of the sex of the other fetuses occupying that uterine horn.

Intrauterine position also affected placental weight of male and female conceptuses. Placentae located at or near the middle of the uterine horn were approximately $10 \%$ heavier than those located at either end. For both sexes, placental weight was inversely related to the number of fetuses present in the ipsilateral and contralateral horns (unpublished data). Within litters, mean placental weight in one horn was positively correlated with that in the contralateral horn, regardless of litter size or sex ratio. For both sexes, there was a positive correlation between the weight of a fetus and that of its placenta (Table 3).

\section{Discussion}

The present findings indicate that the development of a male rat fetus is influenced significantly both by its position within the uterine horn and by the number of littermates with which it shares that horn. 


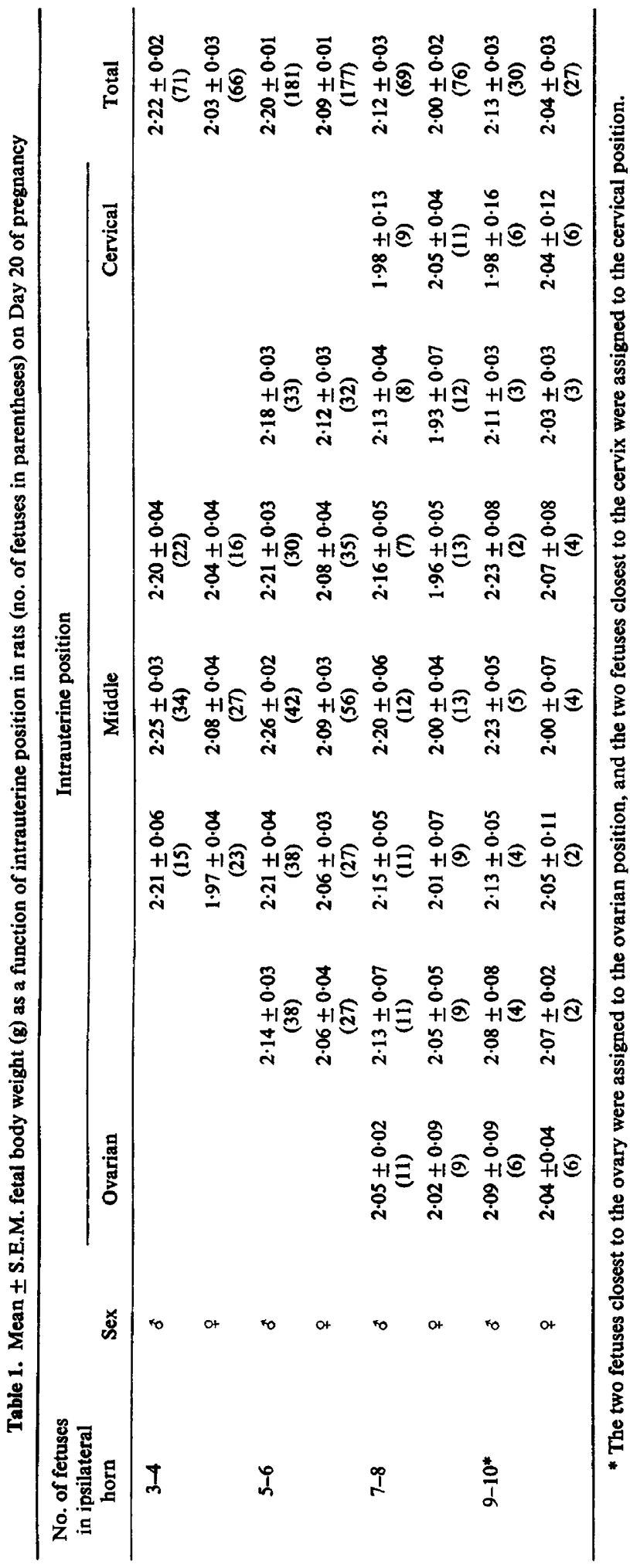




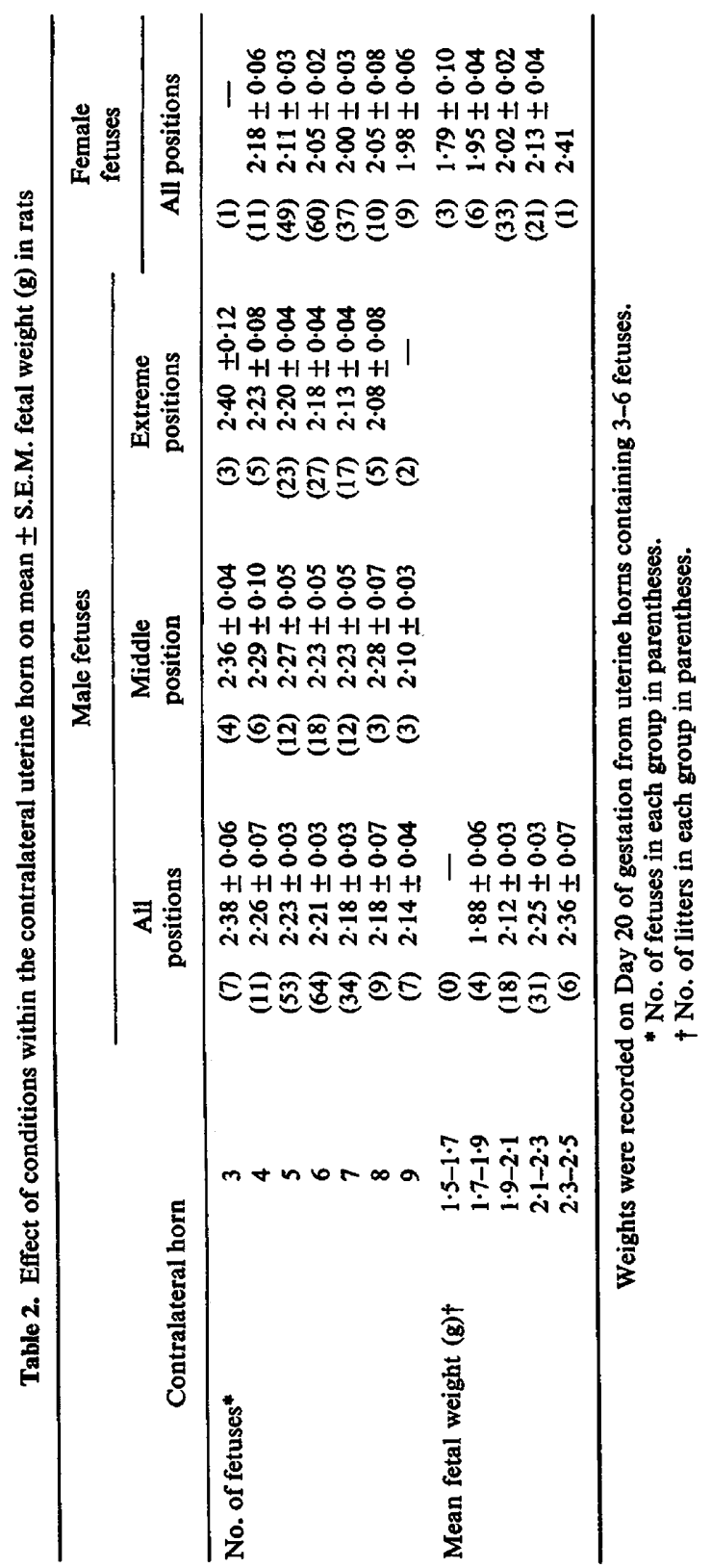


Table 3. Relationship between fetal and placental weights (mean \pm S.E.M.) in rats (no. of fetuses in parentheses) on Day 20 of gestation

\begin{tabular}{crrrr}
\hline & \multicolumn{3}{c}{ Placental weight $(\mathrm{g})$} \\
\cline { 2 - 5 } Fetal weight $(\mathrm{g})$ & \multicolumn{2}{c}{ Males } & \multicolumn{2}{c}{ Females } \\
\hline$<1 \cdot 70$ & $(6)$ & $0.41 \pm 0.01$ & $(14)$ & $0.42 \pm 0.02$ \\
$1 \cdot 70-1 \cdot 90$ & $(25)$ & $0.44 \pm 0.01$ & $(64)$ & $0.46 \pm 0.01$ \\
$1.90-2 \cdot 10$ & $(105)$ & $0.46 \pm 0.01$ & $(177)$ & $0.47 \pm 0.01$ \\
$2 \cdot 10-2 \cdot 30$ & $(152)$ & $0.48 \pm 0.01$ & $(130)$ & $0.47 \pm 0.01$ \\
$2 \cdot 30-2.50$ & $(104)$ & $0.50 \pm 0.01$ & $(36)$ & $0.48 \pm 0.01$ \\
$>2.50$ & $(20)$ & $0.56 \pm 0.02$ & $(0)$ & \\
\hline
\end{tabular}

In contrast, the growth of female rat fetuses appears to be relatively independent of these intrauterine conditions. For male rat fetuses (and for placentae in both sexes), the optimum developmental site is the middle of the uterine horn and the least advantageous site is the extreme ovarian or cervical position, particularly when the horn is occupied by 5 or more fetuses. This pattern of intrauterine position effect has been reported previously in the rat (Barr et al., 1969,1970), and is the reverse of the pattern observed in the guinea-pig (Ibsen, 1928), pig (Waldorf et al., 1957) and mouse (McLaren \& Michie, 1959, 1960; Healy et al., 1960).

Among the explanations proposed for intrauterine position effects, the present data are difficult to reconcile with the hypothesis of differential implantation time (Mossman, 1937). Likewise, considering the distribution of arterial vasculature in the pregnant rat uterus (Barr \& Brent, 1970), these data fail to support the haemodynamic theory of Eckstein et al. (1955), but are consistent with the hypothesis that the rat uterus, being less distendable at the ends than at the centre, imposes mechanical constraints upon fetal development at the termini. In this case, the maximum size attainable at the extreme ovarian or cervical positions is that typical of genetic females.

Genetic sex is one of the most important factors affecting the body weight of 20-day-old rat fetuses (Table 1). Male fetuses are larger than females under all but the most adverse intrauterine conditions. Therefore fluctuations in sex ratio may distort the true relationship between mean fetal weight and intrauterine position if the two sexes are not analysed separately. For example, a female rat fetus located in the centre of a uterine horn containing 2 or 4 additional male fetuses is likely to be the smallest fetus present, not because of her intrauterine position but because of her sex. To ignore fetal sex in a study such as this requires the assumption that the sex ratio at each intrauterine position is similar. Secondary sex ratio is notoriously variable in most mammalian species, and this assumption may not be valid unless the sample size is large. The present study contained 351 male and 346 female fetuses, indicating a sex ratio of 101, but within the subgroups of the experiment the sex ratios varied by as much as $\pm 50 \%$ from the composite ratio.

The negative relationship between male fetal weight and the number of littermates present in the ipsilateral horn may simply be a manifestation of the intrauterine position effect. As the horn becomes increasingly crowded, more males must develop at the disadvantageous ovarian or cervical positions. Their reduced growth potential will be reflected in a reduced mean fetal weight. Certainly crowding per se is not detrimental to the development of male fetuses located in the middle of the uterine horn or the development of female fetuses at any intrauterine site.

In summary, our results suggest that the developmental influence exerted by the uterine environment does not affect male and female rat fetuses equally. The growth of male fetuses is modified by conditions such as position and crowding in the ipsilateral horn; the growth of female fetuses is not. In contrast, the growth of male and female fetuses is influenced by conditions within the contralateral uterine horn.

This work was supported by National Aeronautics and Space Administration grant NGR-47-006054. The dedicated animal care by Ms. D. Reichenbach is appreciated. 


\section{References}

BARcrofT, J. (1944) Nutritional functions of the placenta. Proc. Nutr. Soc. 2, 14-18.

BARR, M. \& BRENT, R.L. (1970) The relation of the uterine vasculature to fetal growth and the intrauterine position effect in rats. Teratology 3, 251-260.

BARR, M., JeNSH, R.P. \& BRENT, R.L. (1969) Fetal weight and intrauterine position in rats. Teratology 2 , 241-246.

Barr, M., Jensh, R.P. \& Brent, R.L. (1970) Prenatal growth in the albino rat: effects of numbers, intrauterine position and resorptions. Am. J. Anat. 128, 413-427.

DixoN, W.J. \& MASSEY, F.J. (1957) Introduction to Statistical Analysis, 2nd edn. McGraw-Hill, New York.

EcksteIn, P. \& McKeown, T. (1955) Effect of transection of one horn of the guinea-pig's uterus on foetal growth in the other horn. J. Endocr. 12, 97-107.

EcksteIN, P., McKeown, T. \& RecoRd, R.G. (1955) Variation in placental weight according to litter size in the guinea pig. J. Endocr. 12, 108-114.

Hammond, J. (1935) The changes in the reproductive organs of the rabbit during pregnancy. Trans. Dynam. Developm. 10, 93-112.

Hammond, J. \& Marshall, F.H.A. (1952) The life cycle. In Marshall's Physiology of Reproduction, Ch. 23. Ed. A. S. Parkes. Longmans Green, London.

Hashrma, H. (1956) Studies on the prenatal growth of the mouse with special reference to the site of implantation of the embryo. Tohoku J. agric. Res. 6, $307-312$.
Healy, M.J.R., Mclaren, A. \& MichIe, D. (1960) Foetal growth in the mouse. Proc. R. Soc. B 153, 367379.

IBSEN, H.L. (1928) Prenatal growth in guinea-pigs with special reference to environmental factors affecting weight at birth. J. exp. Zool. 51, 51-96.

MCCANCE, R.A. (1962) Food, growth and time. Lancet ii, 621-626.

MCCARTHY, J.C. (1965) Genetic and environmental control of foetal and placental growth in the mouse. Anim. Prod. 7, 347-361.

MCCARTHY, J.C. (1967) Effects of litter size and maternal weight on foetal and placental weight in mice. J. Reprod. Fert. 14, 507-510.

MCLAREN, A. (1965) Genetic and environmental effects on foetal and placental growth in mice. J. Reprod. Fert. 9, 79-98.

McLaren, A. \& Michie, D. (1959) The spacing of implantations in the mouse uterus. Mem. Soc. Endocr. 6, 65-74.

MCLaren, A. \& Michie, D. (1960) Control of prenatal growth in mammals. Nature, Lond. 187, 363365.

Mossman, H.W. (1937) Comparative morphogenesis of the fetal membranes and accessory uterine structures. Contrib. Embryol. 26, 129-246.

RosahN, P.D. \& GREeNE, H.S.N. (1936) The influence of intrauterine factors on the fetal weight of rabbits. J. exp. Med. 63, 901-921.

Waldorf, D.P., Foote, W.C., Self, H.L., Chapman, A.B. \& CASIDA, L.E. (1957) Factors affecting fetal pig weight late in gestation. J. Anim. Sci. 16, 976-985. 